\title{
вMJ Global Health The syndemic of COVID-19 and gender- based violence in humanitarian settings: leveraging lessons from Ebola in the Democratic Republic of Congo
}

\author{
Lindsay Stark (D) , ${ }^{1}$ Melissa Meinhart, ${ }^{1}$ Luissa Vahedi, ${ }^{1}$ Simone E Carter (D) , \\ Elisabeth Roesch, ${ }^{3}$ Isabel Scott Moncrieff, ${ }^{3}$ Philomene Mwanze Palaku, ${ }^{4}$ \\ Flore Rossi, ${ }^{4}$ Catherine Poulton ${ }^{3}$
}

\begin{abstract}
To cite: Stark L, Meinhart M, Vahedi L, et al. The syndemic of COVID-19 and gender-based violence in humanitarian settings: leveraging lessons from Ebola in the Democratic Republic of Congo. BMJ Global Health 2020;5:e004194. doi:10.1136/ bmjgh-2020-004194
\end{abstract}

Handling editor Seye Abimbola

Received 13 October 2020 Revised 18 0ctober 2020 Accepted 20 0ctober 2020

Check for updates

\section{(c) Author(s) (or their} employer(s)) 2020. Re-use permitted under CC BY-NC. No commercial re-use. See rights and permissions. Published by BMJ.

${ }^{1}$ Brown School at Washington University in St Louis, St Louis, Missouri, USA

${ }^{2}$ Public Health Emergencies, UNICEF, New York, New York, USA

${ }^{3}$ UNICEF, New York, New York, USA

${ }^{4}$ UNICEF, Kinshasa, Democratic Republic of Congo

Correspondence to Dr Lindsay Stark; lindsaystark@wustl.edu
As the gendered dimensions of COVID-19 are increasingly recognised, efforts to situate gender-based violence (GBV) within the pandemic remain inadequate. It is critical to first acknowledge that the drivers and impacts of COVID-19 and GBV do not occur in isolation; rather, they present as a syndemic — each is made more destructive by the presence of the other. ${ }^{1}$ Thus, it is not the infection of COVID-19 that increases the risk of GBV but rather the gender-insensitive systems and policies that magnify the risk. ${ }^{2}$

Based on the knowledge that the public health crises of violence and infectious disease are intersecting, we use a syndemic perspective to examine their shared influence in humanitarian settings. This brief leverages learnings from the 2018-2020 Ebola outbreak in the Democratic Republic of the Congo (DRC) to inform and strengthen ongoing responses related to GBV and COVID-19 within humanitarian settings.

\section{EXISTING KNOWLEDGE OF GBV IN EMERGENCIES}

GBV encompasses a variety of damaging acts perpetrated against someone based on socially ascribed gender differences. ${ }^{3}$ Systemic inequalities and differences based on patriarchal norms are the root of GBV perpetration and its dire consequences for individuals and society at large. The hegemonic systems that are rooted in gender most often manifest as violence perpetrated by men against women and girls; the adverse influence of these systems increases in humanitarian settings as entrenched norms and inequities are magnified and proliferate during times of crises. ${ }^{4}$

GBV is most often perpetrated inside of the home, as the prevalence of intimate partner

\section{Summary box}

Efforts to situate gender-based violence (GBV) within the COVID-19 pandemic remain inadequate. Based on the knowledge that the public health crises of violence and infectious disease are intersecting, we use a syndemic perspective to examine their shared influence in humanitarian settings.

- When the humanitarian community exclusively prioritises the lives saved from infectious diseases, such as Ebola and COVID-19, the lives impacted by interrelated factors, such as GBV, can be overlooked.

- This narrative leverages learnings from the 20182020 Ebola outbreak in the Democratic Republic of the Congo (DRC) to inform and strengthen ongoing responses related to GBV and COVID-19 within humanitarian settings.

- For both Ebola and COVID-19, response efforts have overlooked the life-saving nature of GBV services. These services, including one-stop crisis centres and safe spaces, are vulnerable to cessation when health service providers attempt to prevent and control the spread of infectious disease without incorporating a gender-sensitive lens.

- A critical opportunity to integrate women within response planning is through local women's organisations which are already embedded in local communities.

violence exceeds other forms of GBV. ${ }^{5}$ Given that humanitarian crises are associated with periods of extreme chronic stress, loss of health and social service infrastructure, and a strained social support network, consequences of all forms of GBV are aggravated, thereby increasing risks such as revictimisation and adverse intergenerational impacts. These risks are also evident during infectious disease outbreaks, leading researchers to identify how women are more affected by men economically, socially and in regard 
to violence victimisation during pandemics. ${ }^{6}$ While emerging evidence links COVID-19 and GBV, less is known in humanitarian settings.

\section{GBV AND COVID-19: A SYNDEMIC PERSPECTIVE}

A syndemic requires that multiple epidemics be inextricably linked and mutually deleterious. GBV and COVID-19 synergistically reinforce the impacts that would otherwise arise if either epidemic occurred in isolation. For example, shelter in place policies may exacerbate domestic violence where women and girls are isolated and living with an abuser. Simultaneously, reduced economic opportunities may drive women and girls to transactional and survival sex, possibly increasing the transmission of COVID-19. Syndemics are also entrenched in the geographical or temporal setting in which they are immersed $^{1}$; humanitarian settings create conditions that are ripe for syndemics given the fundamental breakdown of economic, political and social systems. Thus, managing syndemics, such as GBV and COVID-19, requires not only addressing each but also the context: conflict, displacement, norms and inequities. We must also be cognisant of the intersectionalities that magnify the deleterious impact of the syndemic among certain groups of women and girls in humanitarian settings. This is not the first time we have seen these intersections; we can distil useful lessons from the 2018-2020 Ebola outbreak in the DRC to inform our current syndemic. ${ }^{7}$

\section{KEY LEARNINGS FROM THE 2018-2020 EBOLA RESPONSE IN THE DRC}

The DRC is known to have a high prevalence of GBV with $68 \%$ of women reporting lifetime exposure to physical, sexual or emotional violence. ${ }^{8}$ Moreover, researchers estimate that an estimated 48 rapes occurred every hour in the DRC within the year prior to the 2007 Demographic Health Survey. ${ }^{9}$

The 2018-2020 Ebola outbreak in the DRC saw a notable increase in the reported risk and experience of violence, especially among women and girls. Communities reported an increased incidence of sexual and physical violence and increased sexual exploitation and abuse of women and girls. ${ }^{10} 11$ Gender norms became further entrenched, increasing tasks required of women and girls, including tending to the sick while simultaneously managing household responsibilities. ${ }^{1012}$ Adolescent girls in the DRC indicated that fetching water during unusual hours or over long distances increased their risk of sexual violence during the Ebola outbreak. ${ }^{10}$ Both women and girls, including pregnant women, reported that fear of contracting Ebola was a primary reason they avoided services. ${ }^{10}$ Those who were able to access health services during the Eastern DRC Ebola outbreak encountered reduced overall quality of services. ${ }^{10} 11$ With the restriction of other GBV services, such as safe spaces, women and girls also had fewer opportunities to engage with their social networks, connect with services and physical distance from abusers. ${ }^{11} 13$

These challenges during the Ebola outbreak were of critical concern given the lack of accurate financial resources available to women and girls ${ }^{14} 15$ and the inadequate engagement of women and girls within planning and response efforts. ${ }^{11} 14$ Additionally, work by Translators without Borders identified that the Ebola response in the DRC failed to communicate in ways that resonated with women including the language used, formatting of discussion and source of communication initiation. ${ }^{15}$

\section{FROM EBOLA TO COVID-19: WHAT CAN WE DO NOW?}

Governments have implemented drastic measures to combat COVID-19, but integrated efforts are vital to explicitly address the linkage of the COVID-19 and GBV syndemic. First, actors responding to the COVID-19 pandemic need to be mindful that the inclusion of women cannot be an afterthought or a quota to be filled. We have seen diminishing involvement of women, despite countrylevel guidance in Iraq, Libya, Nigeria and Sudan recommending increased representation of women in decisionmaking positions. Local women's organisations should be integrated within response planning, not relegated to risk communication and community engagement. These women, who are embedded in their respective communities, are best situated to think about how design and roll out measures related to COVID-19 can be done in a way to mitigate GBV risks. Moreover, local women's associations may support an intersectional understanding of the violence experienced by different groups of women as they provide a platform to connect with women who may otherwise be overlooked or unheard in aggregate community fora.

Second, the broader impacts of the syndemic need to be integrated into response plans. Evidence of programmatic impact needs to be weighed routinely, systematically and equitably across interventions; to do so, the humanitarian community needs to stop assuming that lives saved from COVID-19 infection matter more than the lives impacted by interrelated factors, such as GBV. Identifying and supporting women as a vulnerable group within the syndemic framework of programming and policy is an important first step. Given the magnified social and structural violence faced by certain groups of women, these programmes and policies should also use intersectional praxis by highlighting the importance of supporting the unique needs of certain women and girls, such as ethnic or religious minorities and those with disabilities.

Third, GBV programming needs to be mainstreamed across sectors, designated as essential, resourced to operate under new models that take into account COVID-19 and mobilised in ways that promote sustainability. For both Ebola and COVID-19, response efforts have overlooked the life-saving nature of GBV services. These services, including one-stop crisis centres and safe 
spaces, are vulnerable to cessation when health service providers attempt to prevent and control the spread of infectious disease without incorporating a gendersensitive lens. Adhering to stringent guidelines to prevent the spread of COVID-19, mobile health clinics may be particularly appealing to women and girls as these clinics increase physical accessibility and may minimise exposure to COVID-19 due to reduced travel and hospital wait time. Other programmatic considerations that support women and girls that should be integrated into recovery planning include integrating gender-sensitive social safety net within livelihood programming, alleviating caregiving responsibilities or providing childcare options, and addressing the lost peer support and education opportunities for girls.

\section{CONCLUSION}

Urgent response is imperative as women and girls are disproportionately affected by the syndemic of GBV and COVID-19, particularly in humanitarian settings. Carefully considered multilateral and localised policies and programming are essential to addressing the ever-expanding needs of communities impacted by the syndemic. Policy-makers and practitioners, alike, should heed the learnings from the 2018-2020 outbreak of Ebola in the DRC to mitigate against further exacerbation of GBV, prevent future perpetration of GBV and improve supports for GBV survivors.

Twitter Luissa Vahedi @LuissaVahedi and Simone E Carter @simone_tweets

Acknowledgements The authors would like to thank the Social Science Analysis Cell (CASS) for supporting the access to information. The CASS data come from local research teams, the structure is set up by the DRC Ministry of Public Health, and all of the work is a result of local teams and national counterparts.

Contributors LS led the development of this Commentary and had final responsibility to submit the paper for publication. LS and MM led conceptual development with insights from CP, ISM, FR and SEC. MM conducted the initial literature review. CP, ER, ISM, FR, LV, LS and SEC provided complementary literature. LS, LV and MM contributed to manuscript drafting with interpretations provided by CP, PMP, ER, ISM, FR and SEC. All authors reviewed and approved the final manuscript prior to submission.

Funding This commentary was funded by UNICEF, PCA \#20 190101.

Competing interests None declared.

Patient consent for publication Not required.

Provenance and peer review Not commissioned; internally peer reviewed.

Data availability statement There are no data in this work.
Open access This is an open access article distributed in accordance with the Creative Commons Attribution Non Commercial (CC BY-NC 4.0) license, which permits others to distribute, remix, adapt, build upon this work non-commercially, and license their derivative works on different terms, provided the original work is properly cited, appropriate credit is given, any changes made indicated, and the use is non-commercial. See: http://creativecommons.org/licenses/by-nc/4.0/.

\section{ORCID iDs}

Lindsay Stark http://orcid.org/0000-0002-8775-9735

Simone E Carter http://orcid.org/0000-0003-3818-3538

\section{REFERENCES}

1 The Lancet. Syndemics: health in context. Lancet 2017;389:881.

2 Roesch E, Amin A, Gupta J, et al. Violence against women during covid-19 pandemic restrictions. BMJ 2020;369:m1712.

3 IASC. IASC guidelines for integrating gender-based violence interventions in humanitarian action, 2015. Available: https://inte ragencystandingcommittee.org/working-group/iasc-guidelinesintegrating-gender-based-violence-interventions-humanitarianaction [Accessed 22 Sept 2020].

4 Stark L, Wessells M. Sexual violence as a weapon of war. JAMA 2012;308:677-8.

5 Stark L, Ager A. A systematic review of prevalence studies of gender-based violence in complex emergencies. Trauma Violence Abuse 2011;12:127-34.

6 Wenham C, Smith J, Davies SE, et al. Women are most affected by pandemics - lessons from past outbreaks. Nature 2020;583:194-8.

7 Carter SE, Gobat N, Pfaffmann Zambruni J, et al. What questions we should be asking about COVID-19 in humanitarian settings: perspectives from the social sciences analysis cell in the Democratic Republic of the Congo. BMJ Glob Health 2020;5:e003607.

8 Tlapek SM. Women's status and intimate partner violence in the Democratic Republic of Congo. J Interpers Violence 2015;30:2526-40.

9 Peterman A, Palermo T, Bredenkamp C. Estimates and determinants of sexual violence against women in the Democratic Republic of Congo. Am J Public Health 2011;101:1060-7.

10 Kapur N. Gender analysis: prevention and response to Ebola virus disease in the Democratic Republic of Congo, 2020. Available: https://www.care-international.org/files/files/Ebola_Gender_ Analysis_English_v2.pdf

11 IRC. 'Everything on her shoulders:' Rapid assessment on gender and violence against women and girls in the Ebola outbreak in Beni, DRC, 2019. Available: https://www.rescue.org/sites/default/files/ document/3593/genderandgbvfindingsduringevdresponseindrcfinal8march2019.pdf

12 Carter SE, Dietrich LM, Minor OM. Mainstreaming gender in WASH: lessons learned from Oxfam's experience of Ebola. Null 2017;25:205-20.

13 IRC. République démocratique du Congo rapport d'évaluation pour planification post-ebola, 2020. Available: https://reliefweb.int/sites/ reliefweb.int/files/resources/rapportpost-ebolairc2020_0.pdf

14 CASS. Social science support for COVID-19: lessons learned brief 2 - gender inclusiveness in COVID-19 humanitarian response operations, evidence from social sciences outbreak research, 2020. Available: https://www.unicef.org/drcongo/sites/unicef.org.drcongo/ files/2020-05/CASS-Brief2-Gender.pdf

15 Hasan MM. Missing the mark? people in eastern DRC need information on Ebola in a language they understand: a rapid language needs assessment in Goma, DRC, 2019. Available: https:// translatorswithoutborders.org/wp-content/uploads/2019/03/DRC Ebola_Assessment_English.pdf 